\title{
Los precios de café en la producción y las exportaciones a nivel mundial \\ Esther Figueroa-Hernández ${ }^{1}$ \\ Universidad Autónoma del Estado de México, México \\ Francisco Pérez-Soto ${ }^{2}$ \\ Universidad Autónoma Chapingo, México \\ Lucila Godínez-Montoya ${ }^{1}$ \\ Universidad Autónoma del Estado de México, México \\ Rebeca Alejandra Perez-Figueroa ${ }^{3}$ \\ University of Bristol, United Kingdom \\ (Primera recepción: 9/julio/2017, última recepción: 21/mayo/2018, aceptado: 31/julio/2018)
}

\section{Resumen}

Para analizar el efecto de los precios de los grupos de café clasificados por la Organización Internacional del Café (OIC), así como los precios de la bolsa de valores de Nueva York y de Londres, en la producción y las exportaciones del aromático. Se elaboraron dos modelos que fueron estimados mediante regresión de componentes principales. Para verificar la relación de la producción mundial se usaron como variables explicativas la exportación y los distintos precios; para el caso de las exportaciones fueron la producción y los precios. Se concluyó que la cantidad producida de café tiene una relación inversa con las exportaciones del producto y directa con los precios de robusta y de la bolsa de futuros de Londres; en cambio para las exportaciones fueron los precios futuros de la bolsa de Nueva York, el de los naturales brasileños y el de otros suaves. Es decir, los precios internacionales fueron los que influyeron en mayor medida en la variabilidad de la producción mundial y las exportaciones de café.

Clasificación JEL: A10, C01

Palabras clave: producción de café a nivel mundial, precios de café de la OIC, exportaciones de café, precios futuros de Nueva York y Londres, componentes principales

\section{Coffee prices in production and exports worldwide}

\section{Abstract}

To analyze the effect of prices of coffee groups classified by the International Coffee Organization (ICO), as well as the prices of the New York and London stock exchanges on the production and exports of coffee, two models were developed and estimated by principal component regression. Export and different prices were used as explanatory variables to verify the relation of world production. In the case of exports, production and prices were used. It was concluded that the quantity of coffee produced has an inverse relationship with the exports of the product and a direct relationship with the prices of Robusta and of the London futures exchange; while for exports, it was the future prices of the New York stock exchange, those of Brazilian natives, and that of others. This

\footnotetext{
${ }^{1}$ Centro Universitario UAEM Texcoco. Av. Jardín Zumpango S/N Fracc. El Tejocote, Texcoco, Estado de México. C.P. 56259. Tel.: (Oficina) 01 (595)9211216, (celular) 5515665341. E-mail:

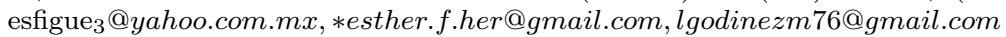

${ }^{2}$ Km. 38.5 Carretera México-Texcoco. C.P. 56230. Tel.: (Celular) 5542315479. E-mail: perezsotofco@gmail.com

${ }^{3}$ Senate House, Tyndall Ave., Bristol, BS8 1TH, UK. Tel.: +44 7487668037, E-mail: rebeca.perezfigueroa@bristol.ac.uk

*Sin fuente de financiamiento declarada para el desarrollo de la investigación
} 


\section{Abstract}

means that the international prices were those that influenced, to a greater extent, the variability of world production and coffee exports.

JEL Classification: A10, C01

Keywords: worldwide coffee production, ICO coffee prices, Coffee exports, New York and London futures exchange, Principal components

\section{Introducción}

A nivel mundial el café ha adquirido gran importancia por su valor total comercial el cual se ubicó en 16500 millones de dólares en 2010, y la producción expedida que ascendió a 97 millones de sacos de $60 \mathrm{~kg}$, "según estimaciones, la producción mundial en el año cafetero 2010/11 alcanzó 131 millones de sacos (7.8 millones de toneladas), mientras que el consumo en 2010 fue de unos 135 millones de sacos (8.1 millones de toneladas)" (ITC, 2011).

De acuerdo con la fuente anterior, "la aportación del café en el total de los ingresos derivados de las exportaciones nacionales superó el $10.0 \%$ en ocho países durante el período 2005-2010, aun cuando la importancia del café en la economía de muchos otros países siguió teniendo una tendencia a la baja (ITC, 2011). Hay alrededor de 70 países que han producido café a nivel mundial, tres de los cuales han representado, sistemáticamente, en estos últimos quince años cerca del $55.0 \%$ del total de la producción mundial: Brasil (32-34\%), Vietnam (12-13\%) y Colombia (8-9\%). Según estimaciones de la Organización Internacional del Café (OIC), en el 2010 trabajaban en el sector 26 millones de personas en 52 de los países productores. Las exportaciones de café no solo constituyeron para muchos países una fuente de divisas de vital importancia para su economía, sino que además formaban una parte considerable del Producto Interno Bruto (PIB), así como del impuesto sobre la renta (ISR) derivado de la comercialización de este producto" (ITC, 2011).

Debido a esto (el aporte que el café representaba en la economía de países productores), se empleó la información disponible que entidades como el Consulado Internacional del Café, la OIC, así como otras fuentes de información (secundaria que provinieron de fuentes oficiales) proporcionaron para analizar y entender de manera más clara el papel que jugaron en el mercado internacional los distintos tipos de precios respecto a la cantidad de café producida y exportada del aromático a nivel mundial.

Este trabajo se dividió de la siguiente manera: la sección 1.1 describe la situación de los componentes del mercado internacional del café. La sección 2 menciona la información y la metodología empleada. En la sección 3 se presentan los resultados obtenidos y, finalmente la sección 4, contiene un resumen de los resultados principales y las conclusiones del mismo.

\subsection{Situación internacional del mercado de café}

La dinámica de la oferta y demanda, así como el comercio internacional de café hasta 1989 era controlada mediante una serie de Acuerdos Internacionales de café, cuyo objetivo era el de mantener precios estables y administrar la oferta de dicho bien. A partir de 1990 el mercado de café ha estado sujeto a un mercado libre de oferta y demanda. En el período que este mercado libre ha estado vigente se han presentado dos periodos de precios bajos (1989-1993 y 1999-2004), siendo el de 1999-2004 conocido como la crisis del café (ICC, 2014). De acuerdo con récords históricos de precios posteriores al fin de esta crisis (2004), éstos han mejorado en relación con los precios durante las dos crisis antes mencionadas, pero la ICC reporta alta variabilidad en los precios debido al incremento de costos de los insumos para la producción de café. 


\subsubsection{Producción}

De acuerdo con información del Instituto del Café de Costa Rica (ICC, 2015), "la producción promedio de Brasil (país históricamente el mayor productor de café a nivel mundial) en las cosechas 2013/14 y 2014/15 fue de $32.6 \%$, seguido en orden de importancia por Vietnam (19\%), Colombia (8.8\%) e Indonesia (7.5\%); en total, los cuatro países aportan alrededor del $60 \%$ de la producción total en ese período". De igual manera, el ICC (2014) reporta que la tendencia de producción mundial de café ha sido positiva entre 1963 a 2013 para tres de las cuatro regiones productoras de café (Asia y Oceanía, América Central y México, América del Sur).

Figura 1. Producción total comercializada de países exportadores, período 1990/91-2015/16 (miles de sacos de $60 \mathrm{~kg}$ )

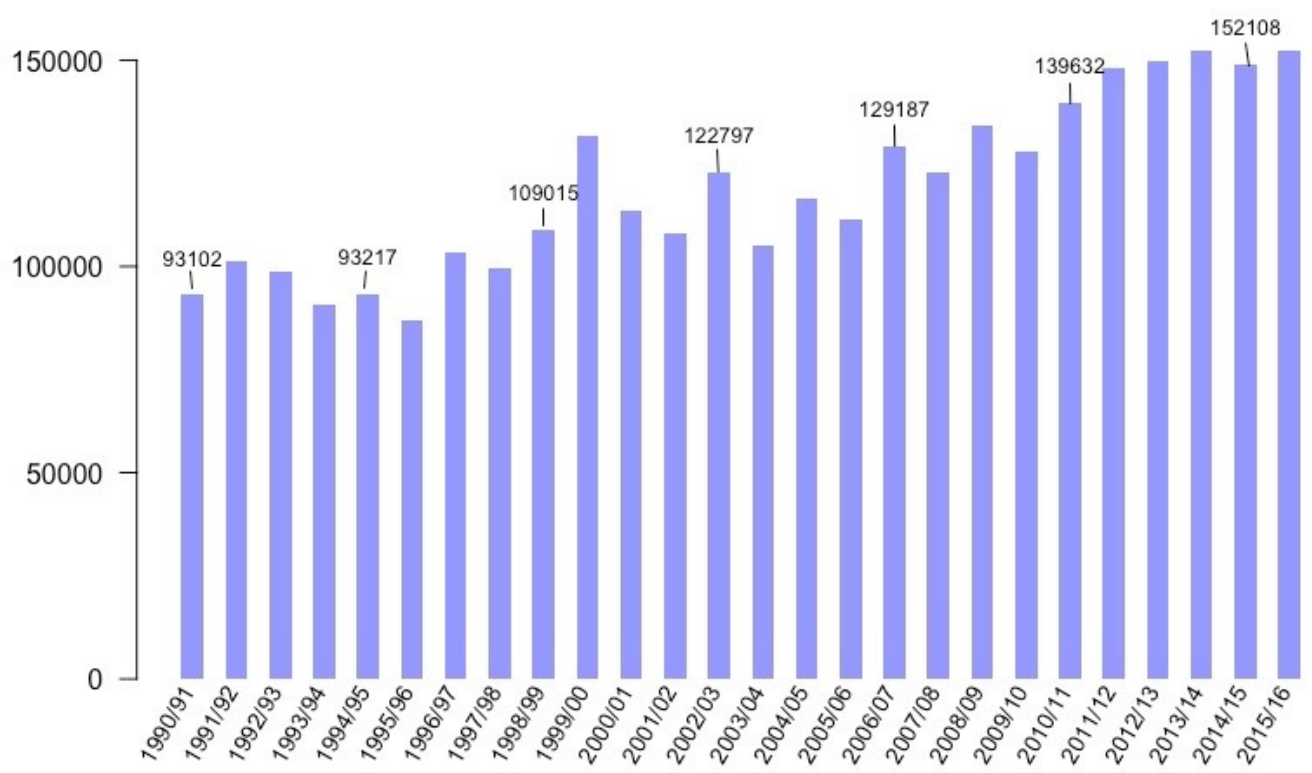

Fuente: Organización Internacional del Café.

De acuerdo con la OIC, en el año cafetero de 1990/91, se produjeron 93102 millones de sacos de $60 \mathrm{~kg}$, para 1999/00, 131496 millones de sacos, en 2010/11 la producción fue de 133989 millones de sacos y para el año 2015/16 de 143371 millones de sacos de $60 \mathrm{~kg}$ (Figura 1).

La producción de café no ha crecido significativamente en los últimos años (Figura 1) y las cotizaciones no muestran una tendencia clara a repuntar. Se destaca, más bien, la merma del café robusta y la retención de sus inventarios. La OIC indicó que mientras los precios de todos los tipos de café registraron descensos durante el mes de mayo, la producción presentó la misma tendencia.

Una de las tendencias en la última década ha sido la del café certificado. Este ha sido generado, como en el mercado de otros productos, como respuesta a las preocupaciones de los consumidores respecto a los efectos en la pobreza, la destrucción del medio ambiente y la injusticia social. Existen beneficios potenciales para los productores que adoptaron estándares de sustentabilidad, incluyendo mejores condiciones de comercio, así como el valor de preservar el medio ambiente; sin embargo, en la actualidad esta práctica no produce los mismos beneficios y ventajas para pequeños productores que en la producción a gran escala (Pierrot et al., 2010; Bennett y Taylor, 2006). 
Figura 2. Participación porcentual de los principales países productores de café a nivel mundial, promedio cosechas, 2013/14 y 2014/15

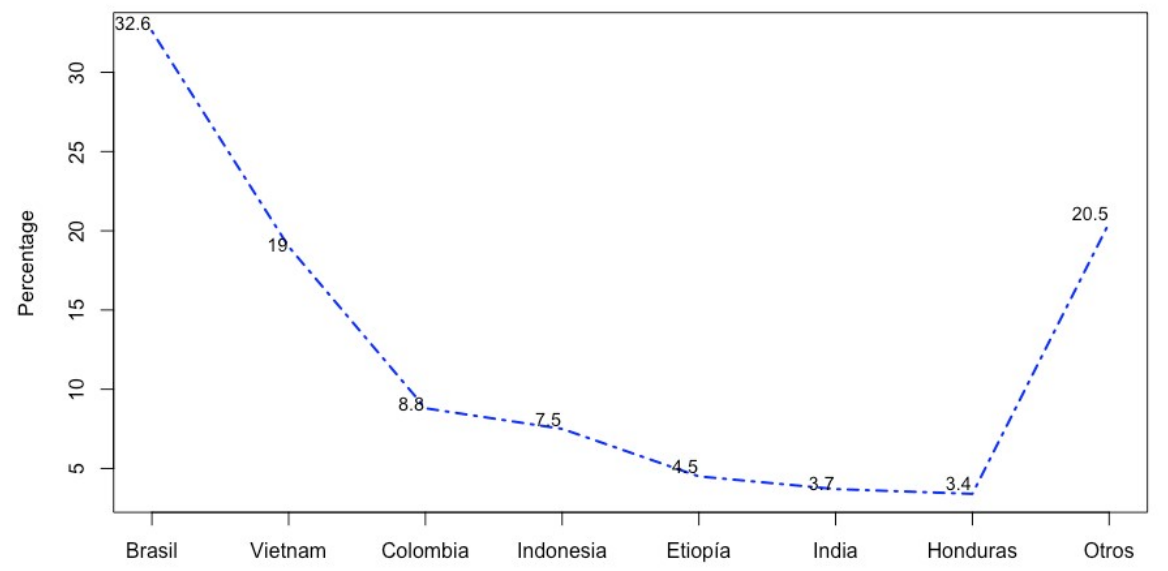

Fuente: Elaborada con datos de la Organización Internacional del Café.

La producción de Colombia para el primer trimestre de 2015/16 era de $25.5 \%$ mayor a la del periodo anterior. Indonesia con una producción de 11 millones de sacos (6.1\%), mientras que Etiopia disminuiría a 6.4 millones (3.4\%) para el mismo período. Para el caso de la India y Honduras se esperaba que aumentará a 5.8 millones (7.0\%). La autoridad de desarrollo cafetero de Uganda suponía un incremento de 4.8 millones $(27.0 \%)$ debido a un incremento de plantaciones. En México, producción para 2014/15 cayó a 3.6 millones de sacos y para el período 2015/16 de 3.9 millones. En Guatemala la producción creció a 3.4 millones de sacos (3.4\%). Por último, para Perú la producción de 2015/16 fue de 3.2 millones de sacos, aunque el volumen de exportación de ese período fue similar al del año previo (OIC, 2015).

Cuadro 1. Países productores de café según el grupo de calidad de la OIC

\begin{tabular}{|c|c|}
\hline Calidad del grupo & Países productores \\
\hline $\begin{array}{l}\text { Arábicas suaves } \\
\text { colombianos }\end{array}$ & Colombia, Kenia, República Unida de Tanzania \\
\hline Otros arábicas suaves & $\begin{array}{l}\text { Bolivia, Burundi, Costa Rica, Cuba, República } \\
\text { Dominicana, Ecuador, El Salvador, Guatemala, Haití, } \\
\text { Honduras, India, Jamaica, Malawi, México, } \\
\text { Nicaragua, Panamá, Papua Nueva Guinea, Perú, } \\
\text { Ruanda, Venezuela, Zambia, Zimbabue }\end{array}$ \\
\hline $\begin{array}{l}\text { Arábicos brasileños y otros } \\
\text { arábicas naturales }\end{array}$ & Brasil, Etiopia, Paraguay \\
\hline Robustas & $\begin{array}{l}\text { Angola, Benín, Camerún, República Central del } \\
\text { África, Congo, Costa de Marfil, República } \\
\text { Democrática del Congo, Guinea Ecuatorial, Gabón, } \\
\text { Ghana, Indonesia, Liberia, Madagascar, Nigeria, } \\
\text { Filipinas, Sierra Leona, Sri Lanka, Tailandia, Togo, } \\
\text { Trinidad y Tobago, Uganda, Vietnam }\end{array}$ \\
\hline
\end{tabular}

Fuente: Elaborado con información de la guía del café, 2011. 
Por distintas razones, la OIC ha clasificado la producción en cuatro grupos con base al tipo predominante de café producido en cada país miembro, aunque en general se producen los dos tipos: arábica y robusta, pero también se puede apreciar el número de países productores según el grupo de calidad en el cuadro 1.

Figura 3. Producción mundial de café por especie, cosechas 2013/14 y 2014/15

$(\%)$

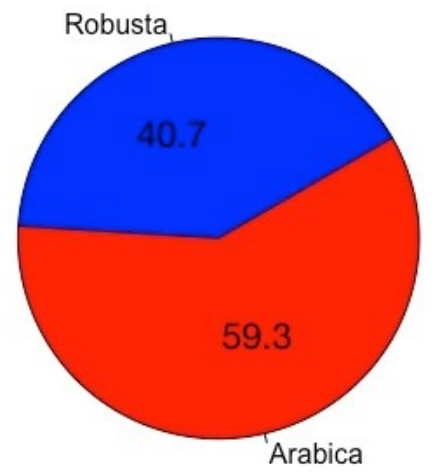

Fuente: Elaborada con datos del Instituto del Café de Costa Rica, 2015.

De la producción mundial de café reportada por la OIC entre las cosechas 2013/14 y 2014/15, el $59.3 \%$ correspondió a la especie arábica y $40.7 \%$ a los robusta (figura 3 ).

"Para la cosecha 2014/15, la producción mundial de ambas especies disminuyó en $2.3 \%$ respecto a la cosecha anterior, mientras que en términos absolutos la disminución en la producción de arábica y robusta fue de 2 y 1.3 millones de sacos, respectivamente" (Instituto del Café de Costa Rica, 2015, p. 10).

De acuerdo con la Compañía Nacional de Abastecimiento (OIC, 2015), la producción de café robusta y arábica en Brasil presento una disminución del $14.2 \%$ y $1.7 \%$ para el año 2015/16 respecto a su valor previo más bajo registrado seis ciclos productivos previos. Sin embargo, esta tendencia a la baja también se presentó en Vietnam, a consecuencia de una caída en las exportaciones del aromático.

Cuadro 2. Producción mundial de café por grupos exportadores, cosechas 2011/12 a 2014/15 (miles de sacos de $60 \mathrm{~kg}$ )

\begin{tabular}{|c|c|c|c|c|c|}
\hline \multirow{2}{*}{ Grupos de café } & \multicolumn{4}{|c|}{ Años de cosecha } & \multirow{2}{*}{$\begin{array}{c}\text { Participación del total } \\
\text { producción } 2014 / 15\end{array}$} \\
\hline & $2011 / 12$ & $2012 / 13$ & $2013 / 14$ & $2014 / 15$ & \\
\hline Producción total & 136571 & 147615 & 146630 & 143252 & 100 \\
\hline Arábicas & 82007 & 88370 & 87010 & 84999 & 59.3 \\
\hline Arábicos lavados & 40565 & 40456 & 40317 & 41187 & 28.8 \\
\hline Suaves colombianos & 8720 & 11523 & 13488 & 14656 & 10.2 \\
\hline Otros suaves & 31845 & 28933 & 26829 & 26531 & 18.5 \\
\hline Brasileños naturales & 41442 & 47914 & 46693 & 43812 & 30.6 \\
\hline Robustas & 54564 & 59245 & 59620 & 58253 & 40.7 \\
\hline
\end{tabular}


El cuadro 2, muestra la distribución de la producción mundial de café de acuerdo con los grupos de países exportadores de café establecidos por la OIC. Los naturales brasileños con una participación de $30.6 \%$ y los arábicos lavados con $28.8 \%$, para el caso del café arábica fue de $59.3 \%$ y de $40.7 \%$ para el robusta con respecto a la producción total de ese año de cosecha 2014/15.

Según estimaciones de la OIC (2015), "la producción mundial de café para 2015/16 fue de alrededor de 143.4 millones de sacos, lo que representó una recuperación de $1.4 \%$ frente a la de 2014/15. La producción total de arábica fue 84.3 millones de sacos frente a 84.4 millones el año previo; esto debido a una baja en la producción de arábicas naturales brasileños y otros arábicas naturales, compensada por aumentos en los suaves colombianos y otros suaves".

En el trabajo de Minh et al. (2016), se menciona la importancia del café como producto para la economía de la población de Vietnam (uno de los países con mayor producción de café a nivel mundial), así como su contribución al PIB. El estudio se centró en analizar los efectos de múltiples variables cuantitativas y cualitativas (área total para producción de café, horas totales de labor por productor, uso de prácticas para controlar la erosión del suelo, métodos de fertilización, etc.) en la producción y productividad de café en una región en particular. Los resultados obtenidos en dicho trabajo mostraron que las variables significativas fueron el área destinada para la producción, el capital invertido, las horas trabajadas y algunas prácticas agrícolas. Estos resultados coinciden con estrategias que se proponen en el trabajo de Quintero y Rosales (2014).

\subsubsection{Exportaciones}

De acuerdo con cifras globales, el volumen total de exportaciones durante las últimas seis décadas ha mantenido una tendencia positiva (durante la vigencia de los acuerdos internacionales y el subsecuente mercado libre). De acuerdo con el ICC (2014), los volúmenes exportados entre 1989 (antes de la suspensión de los acuerdos internacionales) y 2013, se resumieron mediante las exportaciones totales de los ciclos cafetaleros 1989/90, 1994/95 y 2012/13 con valores de 81.3, 65.7 y 111.6 millones de sacos de café, respectivamente.

"El volumen total comercializado por los países exportadores en 2013 fue de 10.6 millones de sacos, un $15 \%$ más bajo que el exportado en 2012 y de 113.945 millones en 2014" (OIC, 2015).

Figura 4. Exportación total mundial de todas las formas de café a todo destino, año cafetalero, 2005/06-2013/14 (millones de sacos de $60 \mathrm{~kg}$ )

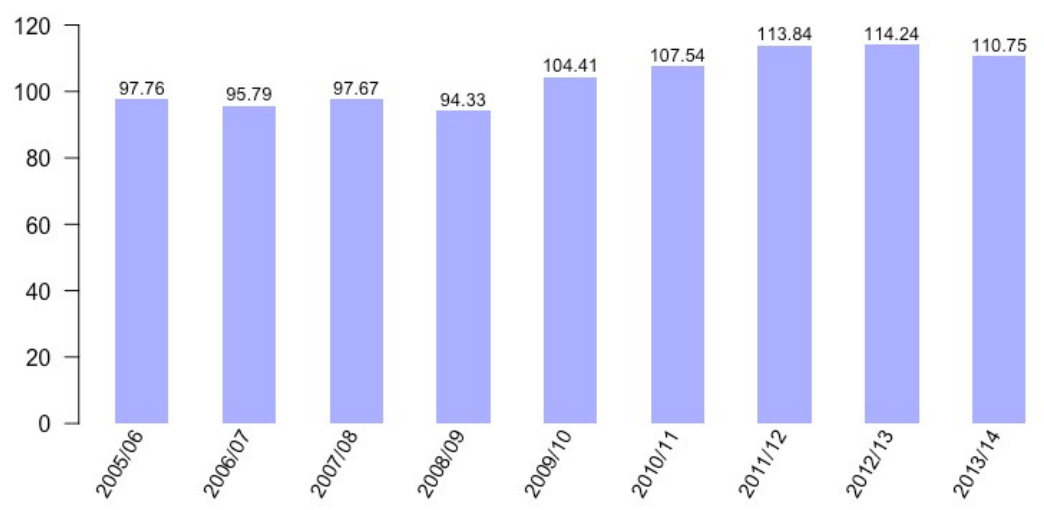

Fuente: Elaborada con datos de la Organización Internacional del Café. 
"De acuerdo con la OIC las exportaciones mundiales de todas las formas de café a todo destino durante el año cafetalero 2014/15 (octubre de 2014 a septiembre de 2015), alcanzaron los 110.75 millones de sacos de $60 \mathrm{~kg}$ (figura 4), lo que represento una disminución del $3.05 \%$ con respecto al mismo período de 2013/14, esta fue la primera disminución de las exportaciones mundiales de café, después de cuatro años consecutivos de marcar una tendencia creciente" (Instituto del Café de Costa Rica, 2015).

Un ejemplo se analizó en Tchalim (2016), que exploró las fluctuaciones de la exportación de café mediante un análisis de la infraestructura de transporte, el cual fue uno de los tres principales productos agrícolas que exportó Toga durante el período 1980-2014. La técnica de modelación empleada fue una transformación logarítmica de un modelo gravitacional para la estimación de café exportado, prueba para determinar estacionalidad o nivel de cointegración y regresión lineal, enfocándose en el efecto de la infraestructura sobre las exportaciones de café. Dentro de las conclusiones de este trabajo, se encontró que el incremento en la infraestructura de transporte tuvo un impacto positivo en la exportación del producto agrícola, el tipo de cambio y el precio de exportación presentaron un efecto negativo y positivo respectivamente sobre las exportaciones.

\subsubsection{Precios}

En cuanto a los precios, los grupos de café que se vendieron en el mundo, arábica, suaves colombianos, otros suaves, arábicas naturales brasileños y otros arábicas naturales descendieron entre 3.4 y $4.4 \%$ durante el mes de junio de 2015. La OIC destacó que la caída más pronunciada fue para el café robusta, de $4.9 \%$, quedando en 0.87 dólares por libra, en promedio, el indicador más bajo en 18 meses. Esto ocasiono que Vietnam, el segundo productor mundial de café frenara sus exportaciones y prefiriera mantener altos sus inventarios, en espera de mejores precios; por lo anterior, de 2.5 millones de sacos exportados por ese país en abril, se bajó a 1.5 millones en mayo. Para la OIC, dos países también presentaron problemas de oferta del grano. En Indonesia, la producción cayó en $23 \%$ (9 millones de sacos), lo que se atribuyó a las condiciones meteorológicas adversas a mediados del año pasado (Portafolio, 12 de junio de 2015).

Figura 5. Índice de precios compuesto y precios para las cuatro categorías de café,

$$
\text { 1990-2017 }
$$
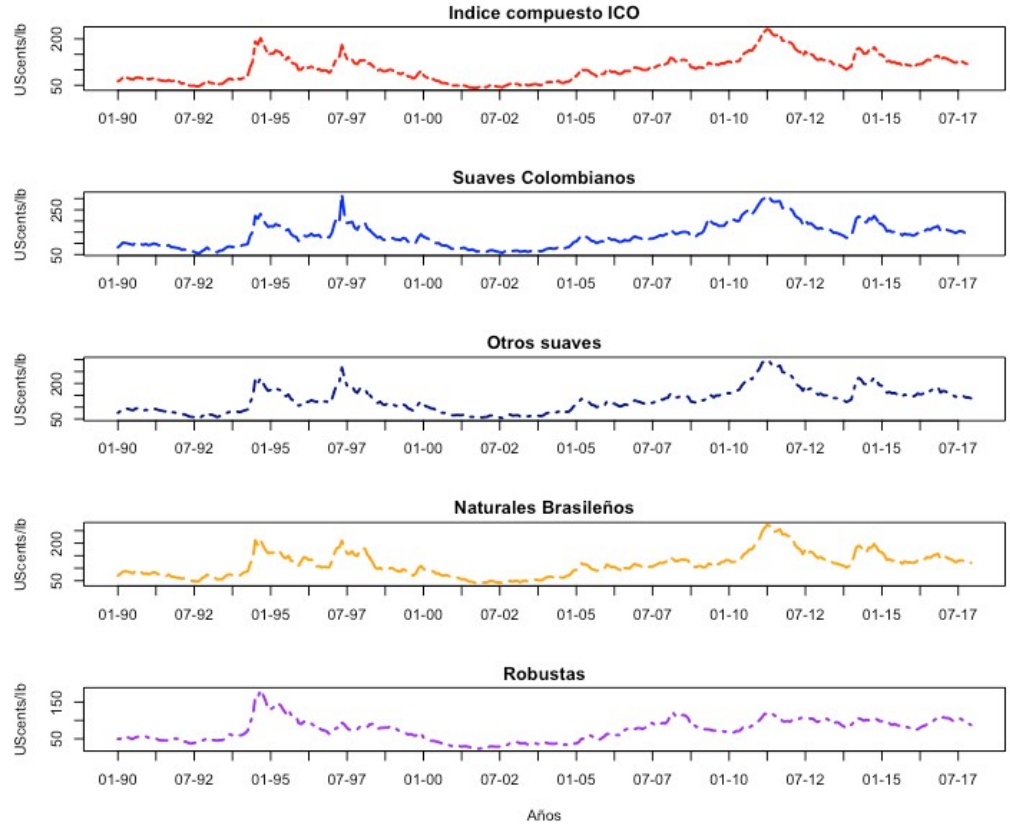

Fuente: Elaboración propia con datos de ICC, 2017. 
Con menor relevancia se presentaron los precios establecidos por la OIC. Estos precios actuaron como indicadores del comercio físico, haciendo referencia a orígenes, calidad, tipo de cambio, destino final de cafés en específico. De acuerdo con Ponte (2002), "el precio indicativo compuesto promedio de la OIC cayó de 69.2 centavos por libra en mayo del 2000 a 56.4 para octubre del mismo año, y llegó hasta 42.2 centavos para octubre de 2001. La volatilidad de precios en el marcado de café no fue rara; un factor importante que dictó dicha variabilidad fue la producción de café, que fue altamente vulnerable a cambios climáticos y enfermedades. Sin embargo, la volatilidad de los precios futuros fue establecida por la relación que hay entre la oferta, la demanda y la bolsa, pero pudo ser magnificado por especulaciones del mercado".

Figura 6. Indicador de precios promedio mensuales para los grupos arábicas colombiano, brasileño y arábicas naturales y robustas (1990-2012)

(Centavos de dólar/libra)

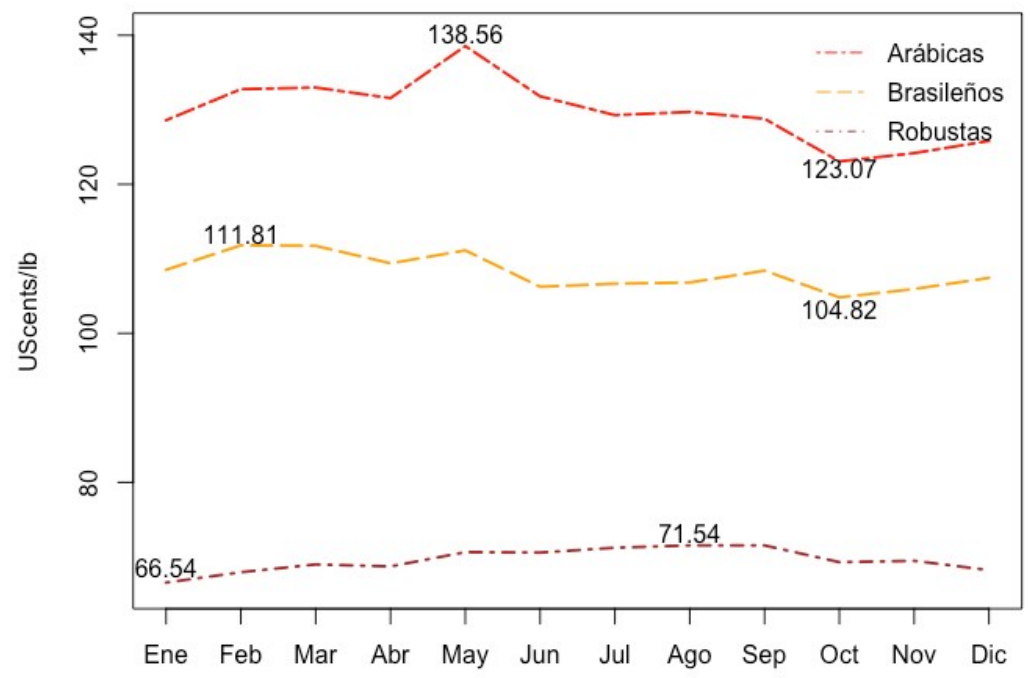

Fuente: http://www.laguiadelcafe.org/guia-del-cafe/el-comercio-mundial-del-

cafe/Exportaciones-mundiales-de-cafe-datos-basicos/,http://www.intracen.org/guia-del-cafe/elcomercio-mundial-del-cafe/Produccion-mundial-por-tipo-de-cafe-arabica-y-robusta/, http://www.aciamericas.coop/IMG/pdf/jchavez.pdf

De acuerdo con las gráficas de precios promedio mensuales, se pudo observar que los precios para el café colombiano disminuyeron en el período de octubre a enero (durante el verano y época de lluvias), probablemente porque hubo mayor producción, mientras que los precios subieron para el resto de los meses, que, aunque febrero-septiembre, fue verano y la producción fue alta en otros países productores, esta producción no rebasó la aportación de Colombia al mercado internacional. Parece que algo similar ocurrió con Brasil, los precios disminuyeron en promedio durante junio-diciembre cuando no era época de lluvias, por lo que su producción disminuyó, por el contrario, los precios de robusta durante mayo-octubre incrementaron y los precios colombianos se mantuvieron casi constantes en el mismo período. Y estos fueron los países que en su mayoría determinaron el mercado mundial de café (Figura 6).

Se llevó a cabo una revisión de literatura con el fin de analizar metodologías empleadas en estudios que compartían características similares a la base de datos utilizados en 
este trabajo. Se encontró que, entre las técnicas más empleadas para el estudio del sistema de producción de café desde un punto de vista económico, la producción y de las exportaciones de café, era la regresión por mínimos cuadrados (OLS), análisis de varianza (ANOVA) en conjunto con algunas técnicas de validación como el factor de inflación de varianza (VIF) y las pruebas de significancia. En el trabajo de Armeanau y Lache (2008), los autores emplearon un análisis de componentes principales al notar redundancia en su grupo de variables para investigar de qué manera influían dichas variables para determinar fortaleza financiera de compañías de seguros en el mercado de seguros en Rumania. En un trabajo más reciente Kichikawa et al. (2015), analizaron 4 categorías de precios: Índice de precios al consumidor, índice de precios de bienes corporativos, índice de precios de importación (para 10 artículos) y el tipo de cambio dólar (USA) a yen (Japón) mediante componentes principales complejos con el objetivo de obtener estructuras de correlación presentes en el sistema de precios japonés.

Otro ejemplo fue el trabajo de Ming-ming y Jing-Lian (2015), en el que al realizar una comparación entre un modelo de regresión lineal clásico y regresión de componentes principales para un set de datos económicos (cantidad importada de un bien, PIB, capacidad de almacenaje y el consumo total del mismo bien) entre 1949-1959, concluyeron que el método que mejor explicaba la variabilidad de las importaciones en el contexto de la situación económica del estudio de caso fue el de regresión con componentes principales, esto debido a que el análisis con el modelo lineal clásico arrojaba resultados inconsistentes.

Un trabajo orientado hacia un análisis de mercado más global fue el de Wadsworth y Richardson (2017), en el que estimaron la tendencia global en los precios de los productos básicos, con el objetivo de analizar si las variaciones en los precios de exportación de carne y productos lácteos de Nueva Zelanda se explicaban en base a la tendencia global en los precios de los productos básicos o por medio de eventos idiosincráticos de cada mercado. Mediante la aplicación de componentes principales obtuvieron una estimación de la tendencia global de productos básicos, emplearon información de 53 precios de productos energéticos, agronómicos y de metales básicos provenientes del Banco Mundial y del índice de precios ANZ (el índice ANZ mide el cambio en el precio de venta de las mercancías exportadas).

Con base en lo anterior, el objetivo del presente trabajo consistió en analizar el efecto de los precios de los grupos de café clasificados por la OIC, de los precios futuros promedios mensuales de la bolsa de Londres y de los precios futuros promedio mensual al cierre de la bolsa de Nueva York sobre la producción y las exportaciones del aromático para los años del análisis (1990-2015). La motivación surge de la falta de un análisis cuantitativo del mercado mundial de café desde un punto de vista global, debido a que aquellos trabajos revisados (de acuerdo con el conocimiento de los autores) se enfocan en una región productora y/o un subgrupo de variables, con la intención de analizar el mercado de una nación en particular. La hipótesis del trabajo suponía encontrar una relación positiva entre la producción mundial de café y los precios para los distintos tipos de café (para los grupos de café de la OIC y futuros promedios mensuales de la bolsa de Londres), así como entre las exportaciones y los distintos precios que recibieron los grupos de café, según la clasificación de la OIC.

El período de estudio comprendido fue de 1990-2015, esto debido a la disponibilidad de la información en las fuentes correspondientes. El escenario ideal sería poder acceder a los datos hasta el año 2017 para todas las variables, sin embargo, algunas de ellas no estaban disponibles hasta 2017. Por esta razón, y debido a que la mayor parte de los datos estaban disponibles hasta 2015, este se delimitó como el período de estudio. 


\section{Materiales y Métodos}

Para la realización de este trabajo, se desarrolló un análisis bibliográfico sobre los aspectos de producción y exportación de café a nivel mundial. En una primera etapa se compiló información de distintas fuentes, entre ellas la del Centro de Estudios para el Desarrollo Rural Sustentable y la Soberanía Alimentaria (CEDRSSA, 2014), la Organización Internacional del Café (OIC, 2015), el Instituto del Café de Costa Rica (ICAFE, 2017), International Coffee Council (ICC, 2011), el Centro de Comercio Internacional (ITC, 2011), el Instituto Hondureño de Café (IHCAFE, 2014), Investing.com (Precios futuros de café, 2017), entre otras, que permitieron obtener los precios de la clasificación de café según la OIC, que afectan la producción y las exportaciones del producto.

Las variables incluidas para la formulación de este trabajo fueron las siguientes: QPCM $=$ producción total mundial de café (millones de sacos de $60 \mathrm{~kg}$ ), POIC $=$ precio de café indicativo de la OIC (centavos de dólar por libra), $\mathrm{PCM}=$ precio de café suaves colombianos (centavos de dólar por libra), $\mathrm{PNB}=$ precio de café de naturales brasileños (centavos de dólar por libra), $\mathrm{POM}=$ precio de café otros suaves (centavos de dólar por libra), $\mathrm{PR}=$ precio de café robusta (centavos de dólar por libra), $\mathrm{ExpC}=$ exportaciones totales de café (millones de sacos de $60 \mathrm{~kg}$ ), PFCLondon $=$ precios futuros promedios mensuales de la bolsa de Londres (centavos de dólar por libra), $\mathrm{PFCNY}=$ precios futuros promedio mensuales al cierre de la bolsa de Nueva York (centavos de dólar por libra).

En una segunda etapa se llevó a cabo un análisis exploratorio empleando diferentes combinaciones de las variables explicativas mediante modelos lineales. Se encontró que, con la producción o las exportaciones empleadas como variable respuesta, los resultados de dichas regresiones lineales mostraron coeficientes no significativos para la mayoría de las variables incluidas; una posible explicación fueron las fuertes correlaciones entre ellas (Robinson y Schumacker, 2009). Estos resultados motivaron el uso de análisis de componentes principales.

Previo a la aplicación de componentes principales, se realizó la prueba de Dickey Fuller para evaluar si la variable dependiente era estacionaria, concluyendo que la producción mundial de café y demás no presentaban una raíz unitaria. En una segunda etapa, se realizó una regresión de componentes principales con el objetivo remover la dependencia lineal de las variables explicativas, $x_{1}, x_{2}, \ldots, x_{p}$, a través de un nuevo conjunto de variables independientes, $y_{1}, y_{2}, \ldots, y_{p}$ donde cada una de éstas es una combinación lineal de las variables originales (se recomienda leer a Everitt, B., 2006 para ver con más detalle el método de regresión de componentes principales).

Para llevar a cabo la regresión con componentes principales, se realizó el cálculo de componentes principales con los datos originales (X) para descomponer las variables originales en una base ortogonal (los componentes principales), para después llevar a cabo la reducción de dimensiones al seleccionar el número de componentes principales 'm' (seleccionar un subconjunto de los componentes principales como variables para predecir ' $\mathrm{Y}$ ') mediante validación cruzada (cross-validation, en inglés), y finalmente realizar la regresión usando los ' $m$ ' componentes principales. Generalmente, se seleccionaron los componentes principales cuyos eigenvalores fueron los más grandes; esto fue, por qué el sub-espacio definido por estos componentes principales capturó la mayor parte de la variación en los datos, por lo tanto, representando un menor espacio en que se creyó que se capturaba la mayoría de las cualidades de los datos. Cabe notar que el método estándar de componentes principales fue una descomposición de 'solo-X' (variables independientes o matriz diseño).

\section{Análisis de resultados}

Con base en la metodología utilizada se obtuvo lo siguiente. Se realizó una gráfica de dispersión (no incluida) como parte de la exploración inicial de la información obtenida. 
De esta figura se pudo destacar la relación lineal bien definida entre las distintas variables de precios, y cómo esta relación se volvía menos pronunciada y definida entre la producción mundial de café y el resto de las variables, así como para la relación entre las exportaciones y el resto de las variables. A pesar del patrón de dispersión que algunos pares de variables mostraron, los valores de correlación para la matriz de datos (fueron en su mayoría altos) expuso valores cercanos a la unidad solo entre las distintas variables de precios, pero valores negativos y cercanos a cero en el caso de $\operatorname{ExpC}$ y $\mathrm{QMC}$ de $\rho=$ -0.09 .

\subsection{Regresión de componentes principales}

Debido a los problemas encontrados durante la estimación de las regresiones lineales con los datos de café, se empleó una regresión de componentes principales (PCR), cuyos beneficios incluyeron la reducción de dimensiones, y la obtención de un nuevo conjunto de variables (componentes principales) ortogonales resolviendo así cualquier posible problema de multicolinealidad (Jackson, 2005; Jolliffe, 1986; Tapia et al., 2001).

De esta manera, se pudieron llevar a cabo las regresiones usando los componentes principales (o un subconjunto de ellos) como las variables explicativas. Usando como base los modelos empleados, se llevaron a cabo las corridas de los modelos por componentes principales para dos casos, usando la producción de café, así como las exportaciones como variables respuesta, lo que se mostró en los cuadros 3 y 4.

Cuadro 3. Salida de la regresión de componentes principales en la estimación de la cantidad producida de café y extracción de coeficientes de la regresión en la estimación de la producción

\begin{tabular}{|l|c|c|c|c|c|}
\hline Coefficients & Estimate & Std. Error & Df & t value & $\operatorname{Pr}(>|\mathbf{t}|)$ \\
\hline ExpC & -1.936 & 0.855 & 24 & -2.26 & $0.032^{*}$ \\
\hline POIC & 0.33 & 0.21 & 24 & 1.57 & 0.129 \\
\hline PCM & 0.094 & 0.303 & 24 & 0.31 & 0.757 \\
\hline POM & 0.083 & 0.277 & 24 & 0.299 & 0.767 \\
\hline PBN & 0.318 & 0.215 & 24 & 1.47 & 0.151 \\
\hline PR & 1.09 & 0.523 & 24 & 2.08 & $0.048^{*}$ \\
\hline PFCLondon & 1.392 & 0.565 & 24 & 2.46 & $0.021^{*}$ \\
\hline PFCNY & 0.265 & 0.262 & 24 & 1.01 & 0.323 \\
\hline
\end{tabular}

Fuente: Elaboración propia.

Para el caso en el que la cantidad producida de café a nivel mundial (QMC) se definió como la variable independiente, los primeros dos componentes principales fueron aquellos que explicaron más del $90 \%$ de la varianza total de los datos. Esto se corroboró al realizar la regresión de cantidad producida de café en función de los componentes principales obtenidos de PCR, decidiendo conservar aquellos cuyo coeficiente resultara significativo al emplear un t-test (al nivel $\propto=0.1$, no incluido).

Posteriormente, al realizar la regresión por componentes principales usando el número óptimo de componentes, se obtuvieron los coeficientes de las variables originales (Cuadro 3 ), donde resultaron significativos (al nivel $\propto=0.05$ ) las exportaciones, los precios de Robustas y los precios futuros de Londres. En el primer paso, se tuvo que establecer que aproximadamente el $90.0 \%$ de la producción mundial de café se llevaba a cabo en países en desarrollo, mientras que el consumo se concentraba principalmente en economías desarrolladas (Ponte, 2002).

El rol de las exportaciones de café con la producción mundial del mismo indicó una relación inversa, esto fue porque las exportaciones no fueron dictadas por la cantidad de café producida en algún país en específico. Las exportaciones de café dependen directamente de los precios internacionales, la demanda del producto a nivel mundial, el tipo 
de cambio para los países productores, entre otros factores (Hong, 2016; Ponte, 2002). De acuerdo con la literatura, los precios de exportación de café en el mercado mundial obedecen la regla de oferta y demanda y un ciclo de negocios de 7 años, tiempo después del cual, los precios de café a nivel mundial parecen sufrir un colapso (International Coffee Council, 2014). De acuerdo con Hong (2016), los precios de exportación para algún país se derivaron de los precios de otros productos compitiendo en el mercado mundial, el tipo de cambio, así como factores de desarrollo para tal país como costos de producción, nivel tecnológico, ingreso, etc.

Para el segundo caso (cuadro 4), la regresión de componentes principales se empleó para analizar el comportamiento de las exportaciones como variable respuesta. De acuerdo con los resultados obtenidos de las regresiones lineales mencionadas anteriormente, se denotó la importancia de los distintos precios en el comportamiento de las exportaciones a nivel mundial del aromático. Como en el caso anterior, se calculó la regresión empleando todos los componentes principales, posteriormente aplicando un t-test a los coeficientes de dicha regresión con el objetivo de determinar el número de componentes a retener para realizar la PCR final. En este caso, se determinó emplear dos componentes que en total explicaron un poco mas del $90.0 \%$ de la varianza total de los datos (no incluido).

Cuadro 4. Salida de la regresión de componentes principales en la estimación de las exportaciones y extracción de coeficientes de la regresión en la estimación de las exportaciones

\begin{tabular}{|l|c|c|c|c|c|}
\hline Coefficients & Estimate & Std. Error & Df & t value & $\operatorname{Pr}(>|\mathbf{t}|)$ \\
\hline QMC & -3.376 & 2.771 & 24 & -1.218 & 0.235 \\
\hline POIC & 1.059 & 0.575 & 24 & 1.84 & 0.078. \\
\hline PCM & 1.601 & 0.805 & 24 & 1.987 & 0.058. \\
\hline POM & 1.554 & 0.743 & 24 & 2.089 & $0.047^{*}$ \\
\hline PBN & 1.26 & 0.509 & 24 & 2.473 & $0.020^{*}$ \\
\hline PR & -0.544 & 1.14 & 24 & -0.477 & 0.637 \\
\hline PFCLondon & -0.611 & 1.285 & 24 & -0.476 & 0.638 \\
\hline PFCNY & 1.562 & 0.623 & 24 & 2.506 & $0.019^{*}$ \\
\hline \multicolumn{7}{|l|}{ Signif. Codes: 0 (***) $0.001^{\text {(**) }} 0.01^{\text {(*) }} 0.05$ '? $0.1^{\text {' }}$} \\
\hline
\end{tabular}

Fuente: Elaboración propia.

$\mathrm{Al}$ analizar el segundo modelo, el de las exportaciones por componentes principales, se retuvieron los primeros dos componentes principales debido a que sus coeficientes resultaron significativos y que el porcentaje acumulado de variación explicada por estos fue mayor al $90 \%$. A pesar de que el coeficiente del PC5 fue significativo, su eigenvalor fue muy pequeño, razón por la cual no se empleó para la regresión PCR final (cuadro 4).

El comportamiento de las exportaciones de café a nivel mundial se pudo explicar en general en base a los precios de los dos tipos de café, así como a los precios futuros, principalmente los de Nueva York (Cuadro 4). Bajo condiciones normales de la oferta, la jerarquía de precios la encabezaron la categoría de suaves colombianos, seguidos por otros suaves, naturales brasileños, y como última categoría, el amplio rango de robustas (Ponte, 2002; McClumpha, 1998).

Otra variable importante fue el precio determinado por la bolsa de futuros de Nueva York para los cafés arábica. Estos representaron el comportamiento del mercado en el corto plazo, en términos de producción, consumo, acciones, pero también factores como riesgos y tendencias futuras. Para establecer los precios futuros, se consideraron los mismos en el mercado físico de cafés arábicos de diversos orígenes y se establecieron como diferenciales en relación con los precios futuros del café, cacao y azúcar estimados por la bolsa de Nueva York. 
Figura 7. Comportamiento de los precios futuros de café en la bolsa Londres y de Nueva York (centavos de dólar por libra)

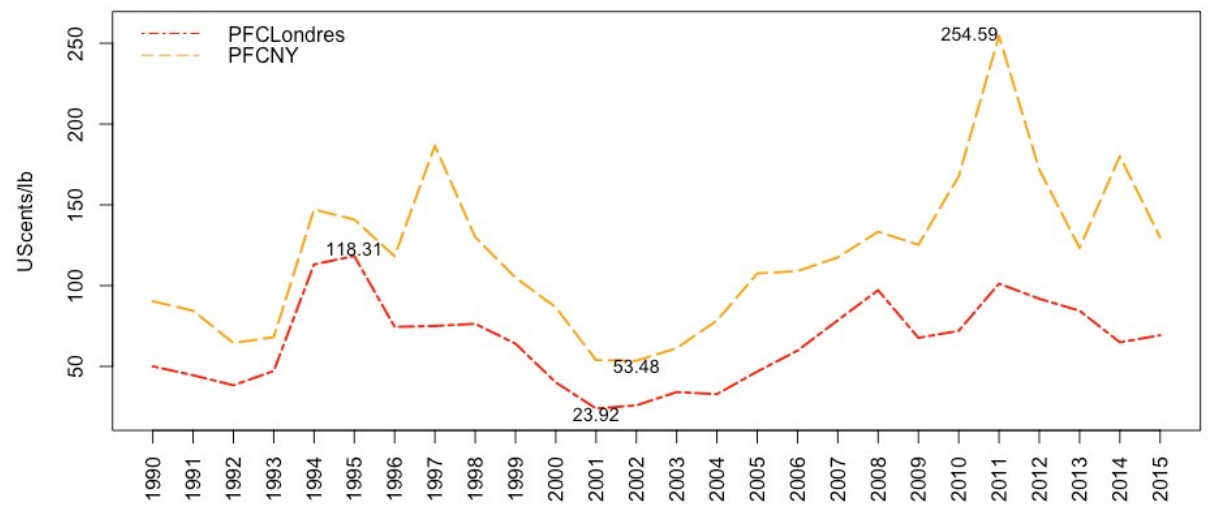

Fuente: Elaborada con datos de:

https://mx.investing.com/commodities/us-coffee-c-historical-data

A partir de la figura 8, se observó que los precios futuros de café de la bolsa de Nueva York han presentado los precios más altos con una tasa de crecimiento media anual de $1.7 \%$ y de $1.5 \%$ para la bolsa de Londres para el período de 1990-2015. De acuerdo con la OIC para el inicio de ciclo 2010/11 se observó un sano equilibrio entre la oferta y demanda mundial. Lo anterior se confirmó al observar los niveles de las cotizaciones internacionales que alcanzaron durante 2010, el máximo histórico en 13 años, 210.39 centavos de dólar por libra, que reflejó el comportamiento del precio indicativo compuesto para el periodo 1990-2015.

\subsection{Elasticidades}

En la obtención de las elasticidades de cualquier modelo, se considerará el concepto ceteris paribus, usarlo permitió estudiar una variable aislada del resto para observar mejor sus cambios cuando las demás variables no se modificaron, es decir, que todas las demás variables permanezcan constantes.

Cuadro 5. Elasticidades de la forma estructural

\begin{tabular}{|c|l|}
\hline$\varepsilon_{E x p C}^{Q P C M}=-1,50495$ & $\varepsilon_{P O M}^{E x p C}=2,192998$ \\
\hline$\varepsilon_{P P C M}^{Q P C M}=0,6843073$ & $\varepsilon_{P B N}^{E x p C}=1,572196$ \\
\hline$\varepsilon_{P F C M}^{Q P C M}=0,7835987$ & $\varepsilon_{P F C N Y}^{E x p C}=2,0633$ \\
\hline$\varepsilon_{P O I C}^{E x p C}=1,21218$ & $\varepsilon_{P C M}^{E x p C}=2,400826$ \\
\hline
\end{tabular}

Fuente: Elaboración propia.

De acuerdo con los valores del cuadro 5, la elasticidad de la cantidad producida de café a nivel mundial con respecto a las exportaciones indicó que si se incrementaran éstas en un $10 \%$ la producción disminuiría un $15.05 \%$. Para el caso del precio de café robusta (PR) y de precios futuros de la bolsa de Londres (PFCLondon), al aumentar en $10 \%$ cada uno de ellos ttendría como consecuencia que la cantidad producida aumentara en 6.84 y $7.83 \%$ respectivamente, es decir, que la cantidad producida de café resultó elástica a las exportaciones (ExpC), e inelástica para los precios de robusta y los precios futuros de la bolsa de Londres. En cambio, las exportaciones de café se mostraron elásticas con respecto al precio de café otros suaves (POM), al precio de café de naturales brasileño, al 
precio futuro promedio mensual al cierre del período de estudio para la bolsa de Nueva York, al precio de café suaves colombianos y el precio indicativo de la OIC; es decir, que si aumentaran en $10 \%$ cada uno de los precios anteriores, las exportaciones de café a nivel mundial, se incrementarán en 21.9, 15.7, 20.6, 24.0 y $12.1 \%$, respectivamente.

\section{Conclusiones y recomendaciones}

Con base en los resultados obtenidos se concluyó que en general, los precios de los distintos grupos de calidad de café de acuerdo con la clasificación de la OIC participaron fuertemente en el comportamiento de la producción mundial y de las exportaciones de este producto, sin embargo, en esta investigación se encontró que principalmente los precios futuros de la bolsa de Nueva York resultaron ser los más influyentes.

Los resultados obtenidos en este trabajo coinciden con lo que establecido por el Instituto del Café de Costa Rica (2017), siendo la importancia del café como un producto comercializado en el mercado internacional, cuyos precios y cantidades producidas son característicamente variables. La tendencia a la baja de los precios del café, han afectado de manera importante los ingresos de los cafetaleros, entre los factores económicos que provocan cambios en la estructura del mercado mundial del café están los costos de producción, los precios internacionales y los cambios climatológicos (CEDRSSA, 2014: p.3), lo que impacta de manera directa al ingreso de 25 millones de agricultores y sus familias, quienes dependen directa o indirectamente de la producción y venta de este producto, llegando a representar hasta el $50.0 \%$ de los ingresos de exportación de algunos países (Instituto del Café de Costa Rica, 2017: p. 3).

Otro factor de gran importancia fueron las deficiencias que enfrentaron los pequeños agricultores de países productores de café, no solo en materia de producción y/o comercialización, sino también en términos de educación y empleo. Es importante recalcar que la mayoría de los países productores de café son economías en vías de desarrollo. Debido a esto, el café se vuelve una fuente de empleo e ingreso para pequeños productores de las distintas naciones cafetaleras (Quintero y Rosales, 2014). En este trabajo se propusieron una serie de estrategias cuyo objetivo fue la mejora socioeconómica de las regiones cafetaleras, a través de una producción de mejor calidad, promover la difusión de información actualizada relevante respecto a la oferta y demanda de café, pero al mismo tiempo encausar la transición hacia métodos de producción más amigables con el medio ambiente, publicidad en un mundo globalizado y, finalmente, disminuir los riegos asociados con la volatilidad de los precios en el mercado cafetalero mediante técnicas de índole administrativo como de participación ciudadana.

Por otra parte, la OIC (2012) y otras organizaciones internacionales propusieron iniciativas para la creación de una economía mundial sustentable del café, que se refieren a una serie de certificaciones para fomentar las prácticas agrícolas amigables con el ambiente, pero de igual manera buscan nivelar la cadena de comercialización y los códigos de conducta, cuyo principal objetivo fue el de mejorar la competitividad de pequeños productores de café en el panorama internacional, lo que mejoraría su economía y calidad de vida pero sin dejar de lado la importancia de preservar el medio ambiente, a través de la implementación o conversión de las prácticas agrícolas tradicionales a la agricultura orgánica, así como un código de ética común entre productores. 


\section{Referencias}

Armeanu, D., and Lache, L. (2008). Application of the model of principal components analysis on Romanian insurance market. Theoretical and Applied Economics, 6(6), 11.

Bennett, D. E., and Taylor, M. J. (2006). Coffee, Conservation, and Livelihood Strategies: A Case Study from Northern Nicaragua.

CEDRSSA. (2014). Producción y mercado de café en el mundo y en México. Centro de Estudios para el Desarrollo Rural Sustentable y la Soberanía Alimentaria (CEDRSSA). Reporte del CEDRSSA. Noviembre de 2014. Recuperado de: www.cedrssa.gob.mx/includes/asp/download.asp?iddocumento= 2756\&idurl $=4576$. Consultado en febrero de 2017.

Everitt, B.S. (2006). An R and S-PLUSR companion to multivariate analysis. Springer Science Business Media. Recuperado de: http://www.springer.com/la/book/9781493970285\#otherversion= 9781493970308. Consultado en febrero de 2017.

Hong, T. T. K. (2016). Effects of Exchange Rate and World Prices on Export Price of Vietnamese Coffee. International Journal of Economics and Financial Issues, 6(4).

IHCAFE. (2014). Informe Estadístico Anual, cosecha 2012-2013. Instituto Hondureño de Café. Recuperado de: www.ihcafe.hn/index.php?/informe estadístico cosecha2012-2013pdf. Consultado en septiembre de 2016 .

International Coffee Council - ICC. (2014). World Coffee Trade (1963-2013): A Review of Markets, Challenges and Opportunities Facing the Sector. International Coffee Council 112th session, London, United Kingdom.

Instituto del Café de Costa Rica. (2015). Informe sobre la actividad cafetalera de Costa Rica. Preparado en el Instituto del Café de Costa Rica para los delegados al XLIV. Congreso Nacional Cafetalero Ordinario Heredia, Costa Rica 6 de diciembre de 2015. Recuperado de: http://www.icafe.cr/ wp-content/uploads/informacion_mercado/informes_actividad/actual/InformeActividadCafetalera. pdf. Consultado agosto de 2016.

Instituto del Café de Costa Rica. (2017). Informe sobre la actividad cafetalera de Costa Rica. Preparado en el Instituto del Café de Costa Rica para los delegados al XLVI Congreso Nacional Cafetalero Ordinario. Heredia Costa Rica. 3 de diciembre de 2017.

ITC. (2011). Guía del exportador de café. Centro de Comercio Internacional (ITC). Tercera edición. Ginebra Suiza. 284 págs. Recuperado de: http://www.intracen.org/The-Coffee-Exporters-GuideThird-Edition/ Consultado en octubre de 2016.

ITC. (2011). La Guía del Café. El comercio mundial del café. Centro de Comercio Internacional. Recuperado de: http://www.laguiadelcafe.org/guia-del-cafe/el-comercio-mundial-del-cafe/ Consultado en octubre de 2016 .

Kichikawa, Y., Arai, Y., and Iyetomi, H. (2015). Complex Principle Component Analysis on Dynamic Correlation Structure in Price Index Data. Procedia Computer Science, 60, 1836-1845.

OIC. (2012). Iniciativas de sostenibilidad. Organización Internacional del Café. Recuperado de: http: //www.ico.org/es/sustaininit_c.asp?section=Acerca_del_cafe. Fecha de consulta: febrero de 2017.

OIC. (2015). Informe del mercado de café. Organización Internacional del Café, diciembre 2015. Recuperado de: www.ico.org/documents/cy2015-16/cmr-1215-c.pdf. Consultado en noviembre de 2016.

Jackson, J. E. (2005). A user's guide to principal components (Vol. 587). John Wiley Sons.

Jolliffe, I. T. (1986). Principal Component Analysis and Factor Analysis. Principal component analysis (pp. 115-128). Springer New York.

McClumpha, A. D. (1988). The trading of Green coffee. In R. J. Clarke, R. Macrae (Eds.), Coffee (volume 6): commercial and technico-legal aspects. London and New York: Elsevier Applied Science.

Ming-Ming, C., and Jing-Lian, M. (2015). Application of Principal Component Regression Analysis in Economic Analysis. Proceedings of the 2015 3rd International Conference on Management Science, Education Technology, Arts, Social Science and Economics. Advances in Social Science, Education and Humanities Research.

Minh, H. T., Trang, D. T. N., and Chen, J. (2016). Input Factors to Sustainable Development of Coffee Production in the Dark Lak Province. Open Access Library Journal, 3(12), 1.

Pierrot, J., Giovannucci, and D., and Katherine, A. (2010). Trends in the trade of certified coffees.

Ponte, S. (2002). The "latte" revolution? Regulation, markets and consumption in the global coffee chain. World development, 30(7), 1099-1122.

Portafolio. (12 de junio de 2015). Los precios y la oferta mundial de café están a la baja. Recuperado de: http://www.portafolio.co/economia/organizacion-internacional-del-cafe-produccion-2015. Consultado en julio de 2016

Quintero R., M. L. y Rosales, M. (2014). El mercado mundial del café: Tendencias recientes, estructura y estrategias de competitividad. Revista Visión general, año 18, núm. 2, julio-diciembre, pág. 291-307. Recuperado de: http://www.saber.ula.ve/bitstream/123456789/39531/1/articulo7.pdf. Consultado en noviembre de 2016.

Robinson, C., and Schumacker, R. E. (2009). Interaction effects: centering, variance inflation factor, and interpretation issues. Multiple Linear Regression Viewpoints, 35(1), 6-11. 
REMEF (The Mexican Journal of Economics and Finance) Los precios de café en la producción y las exportaciones a nivel mundial

Tapia T. G., García G. J., y Odón J. O. (2001). Análisis Factorial y Componentes Principales: su Uso para Modelos Macroeconométricos de la Economía Mexicana. Economía y Sociedad. Año VI, No. 10, octubre 2001, Número de Aniversario. Facultad de Economía "Vasco de Quiroga"de la Universidad Michoacana de San Nicolás de Hidalgo (UMSNH), Morelia, Michoacán. Recuperado de: http://economiaysociedad.umich.mx/ojs_ecosoc/index.php/ecosoc/article/view/313. Consultado en diciembre de 2016.

Tchalim, T. I. (2016). Infrastructure and Coffee Exports' Fluctuations in a Small Open Economy: Case of Togolese Economy. Modern Economy, 7(12), 1419.

Wadsworth, A., and Richardson, A. (2017). A factor model of commodity price co-movements: An application to New Zealand export prices (No. AN2017/06). Reserve Bank of New Zealand.

\section{Páginas web:}

Investing.mx. (2017). Alimentos: Café cotiza cerca de máximo en 4 meses y medio, azúcar sin refinar baja por séptimo día Commodities Futuros, del 9 de agosto. Recuperado de: https://mx.investing. com/news/noticias-de-commodities-futuros/alimentoscafe-cotiza-cerca-de-maximo-en-4meses-y-medio-azucar-sin-refinar-baja-por-septimo-dia-132964

Organización Internacional del Café. Recuperado de: http://www.ico.org/

La guía del café. Recuperado de: http://www.laguiadelcafe.org/guia-del-cafe/el-comercio-mundial-delcafe/Paises-productores-de-cafe-segun-el-Grupo-de-Calidad-de-la-OIC/ Consultado en noviembre de 2016. 